\title{
A Study on Temperature Stress Control Measures of MgO Concrete Dam
}

\author{
Van Chinh Nguyen \\ College of Hydraulic and Environmental Engineering, \\ China Three Gorges University, Yichang, Hubei, \\ 443002, China
}

Van Nghia Nguyen

Division of Hydropower and Renewable Energy, Thuyloi University, Hanoi, Vietnam

Gang Liu

College of Hydraulic and Environmental Engineering, China Three Gorges University, Yichang, Hubei, 443002, China

\author{
Fu Guo Tong \\ College of Hydraulic and Environmental Engineering, \\ China Three Gorges University, Yichang, Hubei, \\ 443002, China
}

Dinh Tuan Phan

Hydraulic Construction Institute, Vietnam Academy for Water Resources, Hanoi, Vietnam

\author{
Chang Liu \\ College of Hydraulic and Environmental Engineering, \\ China Three Gorges University, Yichang, Hubei,
} 443002, China

\begin{abstract}
In recent years, the method of preventing cracks in dam body by adding Magnesium Oxide (MgO) to concrete has attracted more and more attention. This method makes full use of the delayed micro expansion characteristics of $\mathrm{MgO}$ to reduce or compensate the shrinkage deformation of concrete, reduce the tensile stress of concrete dam, and then effectively reduce the possibility of dam cracking. This paper studied the theoretical basis of using MgO to compensate for heat shrinkage, control thermal stress, and limit concrete cracking. After that, an experimental study on the deformation characteristics of $\mathrm{MgO}$ concrete was carried out, and the mathematical model of autogenous volume deformation of $\mathrm{MgO}$ concrete is introduced. Finally, with the Linxihe project as the background, a Threedimensional Finite element method (FEM) numerical simulation model was established to consider the thermal stress compensation efficiency of $\mathrm{MgO}$ concrete by different content. The calculation results show that using the expansibility of $\mathrm{MgO}$ concrete to create effective compressive stress in mass concrete can control thermal stress and improve the crack resistance. The research results have promoted the search for solutions to control temperature and prevent cracking of concrete dams, provided support for more accurate effective concrete dam construction measures.
\end{abstract}

Keywords: Concrete cracking, concrete mixed with $\mathrm{MgO}$, concrete dams temperature controlled, crack prevention, autogenous volume deformation

\section{INTRODUCTION}

A concrete arch dam is a kind of concrete dam with high economic and safety benefits and has a long practical experience. The oldest arch dam in the world was discovered as the Vallon De Baume arch dam (12m high) built in Roman times [1]. The structural characteristics of the arch dam are different from other types of dam: firstly, its external load is mainly through the effect of the arch moving to the two shoulder shoulders, the stress state in the dam is mainly compression stress. The structural characteristics of the arch dam are different from other types of dam: firstly, its external load is mainly through the effect of the arch moving to the two shoulder shoulders, the stress state in the dam is mainly compressive stress. This feature is capable of adapting to the high compressive resistance characteristics of the dam material (concrete or masonry), which promotes the material's power capacity. Secondly, the arch dam's weight mainly through the arch effect to the shoulders, so the stability of the arch dam is mainly based on the rock of the two shoulder dams. In the same position under a similar state of high dam condition, the conventional arch dam is only $1 / 1.5$ to $1 / 5$ of gravity dam, thereby saving construction materials.

The concrete arch dam is a superstatic structure subject to multi-directional constraints. The temperature will greatly affect the stress of the dam body, excessive changes in temperature difference usually produce temperature stress that exceeds the strength of the concrete, which in turn leads to cracks in the dam body. Traditional temperature control measures such as lowering the storage temperature, reducing the adiabatic temperature rise, cooling water pipe, and surface insulation can effectively control the maximum temperature rise of the concrete dam, reduce the temperature gradient, and reduce the temperature stress, thereby preventing the arch dam cracking. However, the above mentioned temperaure control and crack prevention methods usually have the disadvantages of poor economy and large construction interference. Therefore, scientists have been continuously looking for new methods to prevent concrete cracks. In recent years, the method of preventing cracks in dam body by adding Magnesium Oxide $(\mathrm{MgO})$ to concrete has attracted more and more attention. This method makes full use of the delayed micro expansion characteristics of $\mathrm{MgO}$ to reduce or compensate the shrinkage deformation of concrete, reduce the tensile stress of concrete dam, and then effectively reduce the possibility of dam cracking. Fact shows that $\mathrm{MgO}$, after being heated at high temperatures, will naturally inflate during hydration to transform to $\mathrm{MgOH}$., which has good latency, and a unique developmental delay by using this characteristic of $\mathrm{MgO}$, the construction process of mass concrete can be effectively simplified, the concrete cracking of the dam body can be avoided, the construction progress can be accelerated, and the engineering investment can be saved [2], [3]. 
For the reasons mentioned above, the objective of this paper is to summarize and analyze on the causes of concrete arch dam cracking and the expansion characteristics of $\mathrm{MgO}$ concrete in preventing concrete cracking. Moreover, the evaluation of the expansion characteristics of $\mathrm{MgO}$ concrete will be analyzed through actual test results and mathematical models simulating the evolution of autogenous volume deformation of $\mathrm{MgO}$ concrete.

\section{CONCRETE THERMAL CRACKING AND PREVENTION}

\section{A. Cracking phenomenon of concrete}

The cracking phenomenon in some concrete dams both in the world and China is a topical issue. Therefore, studying the causes of cracks and repairing cracks during construction are also scientific issues of particular interest to many people. Accordingly, the cracking phenomenon of concrete is constituted by many factors such as changes in temperature, humidity, heterogeneity of concrete materials, unreasonable dam structure, excessive local stresses, incorrect construction methods. There are many reasons for concrete cracking, including thermal stress and shrinkage which are the most important causes of concrete project cracking during rapid construction, including concrete dams [4]. Because of the poor thermal conductivity of concrete, the temperature in mass concrete blocks will increase very quickly if the temperature does not escape quickly. The increasing or decreasing the temperature in concrete will result in volume change and generate heat stress. When the stress is greater than the allowable tensile strength of concrete, the structure will crack [5]. Not only that, the deformed volume of concrete itself and the inhibitory effect of the external force can lead to cracks in the dam body. Massive concrete dams suffer from the limitations of foundation and the increase of thermal hydration of cement, and due to the mass concrete masses, poor internal heat transfer performance. The occurrence and development of these cracks not only affect the aesthetics of the project, but also destroy the integrity of the concrete dam, change the stress state of the dam, and even result in the concentrated leakage passage of dam, which causes hidden dangers for the dam [6].

\section{B. Measures of cracking prevention}

The pouring blocks of large concrete structures are often very large in size and will be easily affected by temperature. Therefore, in order to ensure the integrity, aesthetics, waterproofness, and longevity of the structure, when designing and constructing concrete works in general and arches dams in particular, must be paid special attention to the generation of thermal stress, reasonable technological measures to prevent thermal cracks. [7].

There are significant scientific means of temperature control during the construction of arch dams, depending on the type of crack and each specific condition, there will be the most appropriate temperature control principle. 1) For surface cracking, it is necessary to thoroughly eliminate the temperature and reduce the temperature difference inside and outside. 2) Due to the temperature control insite concrete has the following two contents: the first is to minimize the temperature difference between the highest temperature of concrete and the stable temperature. On the other hand, it is necessary to make the temperature steady without forming a large slope. 3) The third requirement is to make the dam body rapidly reach the final stable temperature to handle the seal, which loses the threat of relatively large heat stress.

From the aforementioned reasons, it can be seen that controlling the temperature at concrete dams has many tasks, including the highest temperature control and heat escape are the main works [8]. When constructing mass concrete works, the following temperature control measures can be applied: using low heat cement, using optimal mix proportions of concrete to reduce cement content, using larger coarse aggregate, using the activated mineral additives, airentraining admixtures and chemical additives to improve the properties of concrete, pre-cooling concrete aggregate and mixing water to create a concrete mixture with low initial temperature before concrete pouring, using appropriate size concrete pouring block, combining construction schedule and seasonal temperature changes to determine the height of each concrete layer and the intensity of concreting, curing concrete surface which takes place immediately after concrete placing and finishing, and involves maintenance of desired moisture and temperature conditions, both at depth and near the surface, for extended periods of time, heat dissipation with the cooling pipe has been partially positioned into the concrete, insulating surface to minimize the temperature difference between inside and outside the concrete block.

\section{Application of $\mathrm{MgO}$ concrete in arch dams}

In order to control the temperature in concrete, some typical methods are used including using the cooling water pipe, precooling aggregate, increasing construction time, adding fly ash, and other traditional temperature control methods. Although these methods contribute effectively to the control of concrete temperature in the dam, they increase construction time and cost money. Therefore, scientists have been continuously looking for new methods to prevent concrete cracks, including the addition of $\mathrm{MgO}$-type expansion agents that can compensate for shrinkage of concrete and relieve the cracking risk [9], because the addition of magnesium oxide may cause expansion deformation [10]-[14]. This approach was first developed in China in the 1970s when the Chinese researchers and engineers discovered that the thermal shrinkage of mass concrete in the Baishan Dam was effectively compensated by the delayed expansion due to the slow hydration of the periclase contained in the cement clinker, and thus thermal shrinkage cracking was minimized [15]. Then, Chinese researchers and engineers focused on the research of the hydration and expansion of high $\mathrm{MgO}$ containing expansive cement [16], [17], and their compensation effects on the thermal shrinkage of mass concrete. In recent years, with the continuous deepening of research, $\mathrm{MgO}$ concrete dam construction technology has been used more and more. The use of $\mathrm{MgO}$ concrete, supplemented by other appropriate measures, can partially replace traditional concrete dam temperature control measures. This will not only help solve the cracking problem of concrete dams, but also enable continuous pouring of long 
blocks, thick layers, shorten the construction period, and greatly speed up the construction progress, so it has significant technical and economic advantages and application development prospects in China.

Reality has shown that $\mathrm{MgO}$ after being heated at high temperatures, will naturally inflate during hydration to transform to $\mathrm{MgOH}$, which has good latency, and a unique developmental delay by using this characteristic of $\mathrm{MgO}$, the construction process of mass concrete can be effectively simplified, the concrete cracking of the dam body can be avoided, the construction progress can be accelerated, and the engineering investment can be saved. During 50 years of experience in the use of $\mathrm{MgO}$, several studies have shown that the thermal shrinkage compensation with slowly hydrating $\mathrm{MgO}$ is an effective and economical method to prevent thermal cracking in concrete dams. The application achievements of dam construction technology with $\mathrm{MgO}$ concrete have demonstrated that delayed micro-expansion of $\mathrm{MgO}$ concrete may be used to let the concrete produce appropriate precompressive stress, so as to reduce or balances the tensile stress generated during concrete temperature drop, improve the crack-resisting performance of concrete, and fundamentally resolve the crack control issue of dam concrete [18].

Several laboratory experiments and practical work have shown that when concrete contains a certain amount of $\mathrm{MgO}$, the concrete will undergo autogenous volume deformation after solidification. The process of thermal expansion and shrinkage co-generates at the same time. Therefore, this feature compensates for the temperature shrinkage of the concrete, which is beneficial for preventing cracking. Taking advantage of this property of $\mathrm{MgO}$ concrete to apply to the construction of arch dams, eliminating or simplifying traditional heat control of concrete, and may not or reduce the number of arch dam joint and accelerate dam construction [19]. The key problem of $\mathrm{MgO}$ concrete is to determine the composition of the concrete and the mixing amount of $\mathrm{MgO}$ to make it most reasonable.

History shows the changes in the proportion of $\mathrm{MgO}$ in concrete content. In the $1880 \mathrm{~s}$, cement with $16 \%$ to $30 \%$ $\mathrm{MgO}$ content was used in building bridges in France [20]. In the 1970s, research results at the Liujiaxia and Hengren dams in Jilin province, China demonstrated the reason for fewness cracks, which the autogenous volume deformation (AVD) of $\mathrm{MgO}$ concrete made compensation for shrinkage at a lower temperature. The autogenous deformation of the Liujiaxia dam was $60 \cdot 10^{-6}$ and that of the Hengren dam was $100 \cdot 10^{-6}$ when concrete mixed with $4.5 \%$ to $6 \% \mathrm{MgO}$ content. Baishan Dam used 5\% MgO mixed into the concrete without concrete cracks. This result is the cause of the hydration of $\mathrm{MgO}$ cement [21]. Therefore it can be asserted that the use of $\mathrm{MgO}$ in concrete is an important scientific foundation to improve the autogenous crack prevention of concrete. Previous studies as Lei Guo et al. [15], S. H. Liu et al. [22], P.W. Gao et al. [23] made predictions about the AVD process of $\mathrm{MgO}$ concrete. These studies and applications have shown that the expansion properties of $\mathrm{MgO}$ materials will determine the expandability of $\mathrm{MgO}$ cement. However, the quality of $\mathrm{MgO}$ expansion materials is closely related to production conditions, calcination systems, grinding fineness and particle size distribution, product uniformity and stability. The expansion behavior depends on many parameters including its reaction activity, dosage, mix proportion of concrete, curing temperature and age, etc.

According to the previous statement, traditional techniques for controlling the temperature rise of concrete have been developed relatively. Nowadays, the technology of adding magnesia concrete to construct dams and RCC arch dams which have gradually become a research hotspot. So for thermal stress and temperature control, it is necessary to study the AVD properties of RCC mixed with $\mathrm{MgO}$. Since 1995, the use of $\mathrm{MgO}$ for the entire dam body has been used as the Liujiaxia, Hengren, Panjiakou dam; all of them adopted cement which contained $2 \%$ to $5 \% \mathrm{MgO}$. Since then, the method of adding $\mathrm{MgO}$ into the cement in the factory or adding $\mathrm{MgO}$ into the concrete while mixing was adopted in the dam, such as Shitang, Tongjiezi, Shuikou, Doufeng, Yanjinqiao, Lijiaxia dam, Qingxi, and Feilaixia dams in China [21],[24].

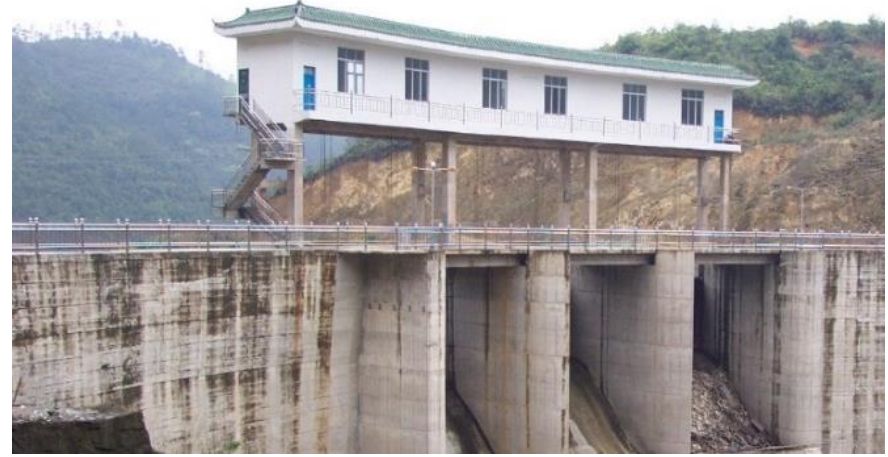

Fig. 1.Downstream view of Changsha Arch Dam [24]

Subsequently, a large number of studies demonstrated that Fushun cement used in Baishan arch dam contained $4.28 \%$ to $4.38 \%$ of $\mathrm{MgO}$, the main cause of expansion, and the expansion of $\mathrm{MgO}$ concrete occurs mainly in the medium term and about $80 \%$ of the expansion occurs in 20 years [25]. The AVD observed by a stress-free meter embedded in Shuikou dam is generally (40 to 60$) \times 10^{-6}$, and conventional concrete measurements are (20 to 30$) \times 10^{-6}$, and the effective expansion deformation is (60 to 80$) \times 10^{-6}$, providing compensatory stress of 0.3 to $0.5 \mathrm{Mpa}$ [26]. The Changsha arch dam used $3.5-4.5 \% \mathrm{MgO}$ in the entire dam section, compensating for thermal stress during construction by using its expansion characteristics. This method simplifies the prevention of concrete cracking like traditional concrete pouring methods such as ice-cooling [27].

TABLE 1 Application of $\mathrm{MgO}$ for concrete dams [28],[29]

\begin{tabular}{lllll}
\hline Dam & $\begin{array}{l}\text { Height } \\
\text { m }\end{array}$ & MgO \% & Joint & Construction time \\
\hline Changsa & 59.5 & $3.5-4.5$ & Without joint & $1-4 / 1999$ \\
tode & 61.2 & $3.5-5.5$ & Without joint & $3-10 / 2001$ \\
Sanjiang & 71.5 & 4.5 & Joints & $10 / 2002-5 / 2003$ \\
Yujinahe & 81 & $3.0-4.0$ & Joints & $11 / 2003-5 / 2004$ \\
Longshou & 80 & $3.0-4.5$ & Joints & \\
Bamei & 53.5 & 5.5 & Without joint & $2-7 / 2003$ \\
Changtan & 53 & $5.5-5.75$ & Joints & $4-12 / 2004$ \\
Luojiaohe & 81 & $5-5.5$ & Joints & $1-10 / 2006$ \\
Macaohe & 69.5 & 6 & Joints & $1-11 / 2007$ \\
\hline
\end{tabular}




\begin{tabular}{lllll}
\hline Dam & $\begin{array}{l}\text { Height } \\
\text { m }\end{array}$ & MgO \% & Joint & Construction time \\
\hline Liaojiangdi & 67 & 5.9 & Joints & $12 / 2007-10 / 2008$ \\
Huanghuazhai & 108 & $2.5-3.0$ & Joints & $1-10 / 2008$ \\
\hline
\end{tabular}

It can be seen from TABLE 1 that the arch dams using $\mathrm{MgO}$ concrete technology are small and medium-sized arch dams (dam height is less than $100 \mathrm{~m}$ ), with an average $\mathrm{MgO}$ content of $4.5 \%$ and a maximum of $6.0 \%$. Early arch dams had almost no cracks, but the simulation analysis of the project found that the expansion of $\mathrm{MgO}$ concrete could not fully compensate for the thermal stress of the dam. If construction measures are not adopted, the concrete dam still has potential cracks. Therefore, for future high dams using $\mathrm{MgO}$ concrete technology, more joints will be arranged to improve the safety of the project.

\section{EXPERIMENTAL STUDY ON THE AUTOGENOUS VOLUME DEFORMATION OF MGO CONCRETE}

\section{A. Expansion mechanism and characteristics of $\mathrm{MgO}$} concrete

$\mathrm{MgO}$ will cause volume expansion during hydration, when adding an appropriate amount of $\mathrm{MgO}$ into concrete can offset part of the volume shrinkage caused by the cooling after pouring and preventing cracking of the concrete. The good anti-cracking effect of $\mathrm{MgO}$ concrete in the Baishan Dam has attracted widespread attention from domestic experts, and has also led to in-depth research on $\mathrm{MgO}$ materials and dam construction technology. Scientists around the world have studied the theory of expansion mechanisms as well as actually studied the expansion process of $\mathrm{MgO}$ concrete. Accordingly, many scholars have proposed a method to describe the expansion deformation process of $\mathrm{MgO}$. The AVD of concrete is essentially the volume expansion caused by cement stones, and the aggregate itself is not expanded. This is the essential difference caused temperature rise between it and concrete. Therefore, as long as the expansion mechanism of cement stones is clear, the expansion mechanism of concrete is clear.

Academician Mingshu Tang [30] of Nanjing University of Chemical Technology, after years of research believing that the calcination of calcined periclase (crystals) at a high temperature is very slow, resulting in spontaneous growth during hydration volume expansion appears later; the formation and development of crystals from hydration are the source of delayed expansion of cement stones, the expansion power of cement stone comes from the swelling power of crystals and the growth pressure of crystals, which is the main motivation for the expansion of cement stone. Because as the crystal developes, the growth pressure of crystal becomes the main motivation for the expansion, the amount of expansion of the cement stone depends on the position of the crystal, its size and its morphology. These are fine brucite crystals concentrated on the surface of the particles that can produce large expansion, brucite crystals in a large area around the rough, dispersed particles causing a small amount of expansion. The expansion properties of cement stone and concrete mainly depend on the quality and content of the expanded materials, the ambient temperature, the type and amount of mineral additives, mineral composition and content of cement clinker. In the next sections, the experimental methods and results are first introduced, followed by the expansive model with the model coefficients are mainly influenced by the content of $\mathrm{MgO}$, the curing temperature and time will be discussed.

\section{B. Experimental results of the AVD process of $\mathrm{MgO}$ con- crete}

A large number of experimental studies and engineering applications show that the expansibility of $\mathrm{MgO}$ cement mainly depends on the expansibility of $\mathrm{MgO}$ material. However, the quality of $\mathrm{MgO}$ expansive material is closely related to the production conditions, calcination system, grinding fineness and particle size distribution, product uniformity and stability. In this paper, the authors focus on the experiment of the AVD process of $\mathrm{MgO}$ concrete under different $\mathrm{MgO}$ content, temperature and curing time conditions. Experimental methods and conditions are referenced in the previous studies of the author [2], [3]. When mixed with $3 \%, 4 \%$ and $5 \%$ $\mathrm{MgO}$, the expansion of the concrete is greater than the shrinkage, so the expansion occurs at a later age. Fig. 2 shows that with the increase of $\mathrm{MgO}$ content in concrete, the AVD process of $\mathrm{MgO}$ concrete also increases. This also demonstrates that when $\mathrm{MgO}$ expansion materials are incorporated into concrete, the shrinkage can be compensated by the hydration of the expansion materials in the concrete [23].

In the early days, the expansion agent in concrete can cause less shrinkage, but at an older age, the expansion is greater, the expansive deformation of concrete with the $\mathrm{MgO}$ type expansive agent might be controlled by blending fly ash in it [31].

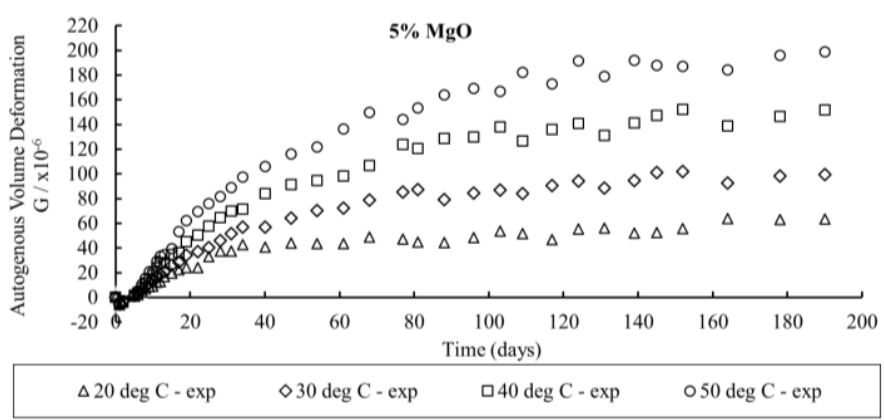

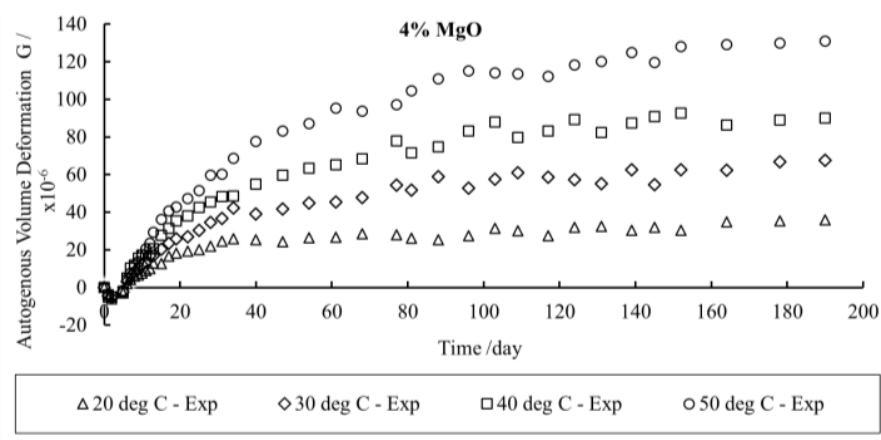




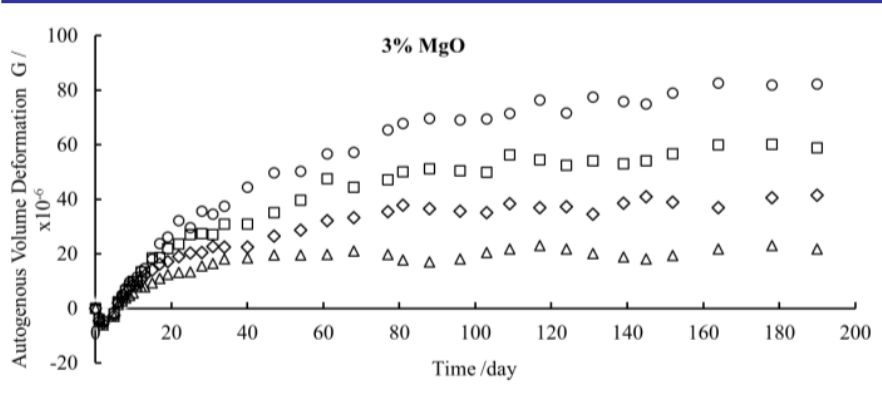

$\Delta 20 \mathrm{deg}$ C - Exp $\quad \diamond 30 \mathrm{deg}$ C - Exp $\quad$ Q $40 \mathrm{deg}$ C - Exp $\quad 050 \mathrm{deg}$ C - Exp

Fig. 2.The AVD of three types of experimental specimens mixed with 5\%, $4 \%$ and $3 \%$ of $\mathrm{MgO}$ content, respectively, under different curing temperature and time conditions [2], [3], [32]

The expansions of concrete with $\mathrm{MgO}$ expansive materials increased with the curing time as shown in Fig. 2 in early age and tended to be constant in later age. The AVD of $\mathrm{MgO}$ concrete increased fast in the period of 190 days, and more slowly after being cured for 190 days. This can be explained by the higher curing temperature causing the paste to swell more, the molecules in the solution activate faster and more $\mathrm{MgO}$ reacts with water, so the hydration of $\mathrm{MgO}$ and the expansion of the paste increase [31].

\section{The mathematical model to simulate the AVD process}

The micro-expansion performance of the $\mathrm{MgO}$ concrete is directly related to many factors, such as the $\mathrm{MgO}$ content, temperature, age, cement type, fly ash content, and $\mathrm{MgO}$ quality. In practical engineering applications, especially scientific experiments to determine the various properties of $\mathrm{MgO}$ concrete, mathematical models should also be proposed to simulate the AVD process. In this section, the author will introduce a mathematical model that fully expands the expansion of $\mathrm{MgO}$ concrete.

$G(t, T)=\frac{t}{\alpha_{1} T^{\alpha_{2}}+\lambda_{1} T^{\lambda_{2}} \cdot t} \cdot c_{1} T^{c_{2}} \cdot 10^{-6}$

where $G(t, T)$ is the AVD equation of $\mathrm{MgO}$ concrete as a function of the curing time $t ; t$ is the curing time (day); $T$ is the temperature $\left({ }^{\circ} \mathrm{C}\right)$, the functions $\alpha_{1} T^{\alpha_{2}}, \lambda_{1} T^{\lambda_{2}}$, and $c_{1} T^{c_{2}}$ are defined by:

$$
\begin{aligned}
& \alpha_{1} T^{\alpha_{2}}=(4.5933 \cdot \ln (M)-3.5595) T^{(-0.9090 \cdot \ln (M)+0.6788)} \\
& \lambda_{1} T^{\lambda_{2}}=(-7.541 \cdot \ln (M)+12.835) T^{(0.4024 \cdot \ln (M)-2.0143)} \\
& c_{1} T^{c_{2}}=(-0.174 \cdot \ln (M)+1.0067) T^{(0.0334 \cdot \ln (M)+0.0272)}
\end{aligned}
$$

where $M$ is the $\mathrm{MgO}$ content (\%). The final equation of the AVD model in Eq. (1) shows the AVD of the MgO concrete which is a function of the $\mathrm{MgO}$ content $(M)$, temperature $(T)$ and curing time $(\mathrm{t})$. This equation is considered to be a relatively complete equation with the components of $\mathrm{MgO}$ content, temperature and curing time as the main factors affecting the AVD process of $\mathrm{MgO}$ concrete. This equation will be used to simulate the deformation of $\mathrm{MgO}$ concrete at any curing temperature and time [2].

\section{EVALUATE THE THERMAL STRESS CONTROL EFFICIENCY OF MGO CONCRETE DAM}

\section{A. Finite element mesh}

As mentioned in the previous section, $\mathrm{MgO}$ is an expansion agent that compensates for the shrinkage of concrete, thereby preventing the thermal cracking of concrete. The selection of $\mathrm{MgO}$ content must meet the stability of the concrete dam because the compensation effect will be different at different dosages. However, solving the thermal problems of $\mathrm{MgO}$ concrete dams is complicated, and the results of temperature calculations depend on many factors. Therefore, in order to establish a scientific and economical concrete dam construction process, it is necessary to study and understand the influence degree and law of basic factors including $\mathrm{MgO}$ about the temperature and thermal stress of concrete arch dams during construction. In this section, a three-dimensional finite element numerical simulation model was established to consider the thermal stress compensation efficiency of concrete mixed with different amounts of $\mathrm{MgO}$ expansion agent. This section simulates the construction process of the Linxihe arch dam, and the sequence of concrete pouring over time through a threedimensional finite element method (FEM). The calculation model is mainly shown in Fig. 3.

For large concrete structures, durability and performance related to temperature state and crack resistance are very important. These are elastic modulus, Poisson coefficient, tensile strength, tensile deformation, variable magnetism, free volume deformation, autogenous volume deformation, thermal expansion coefficient, thermal conductivity, and water permeability. The thermal parameters of concrete mainly refer to the thermal conductivity, the surface heat exchange coefficient between the environment and the concrete, and the autogenous volume deformation. Moreover, attention should be paid to increasing concrete temperature, elastic modulus, and creep deformation, these parameters depend on the age and temperature of concrete. In this study, the calculation model parameters are referenced from V. C. Nguyen [32].

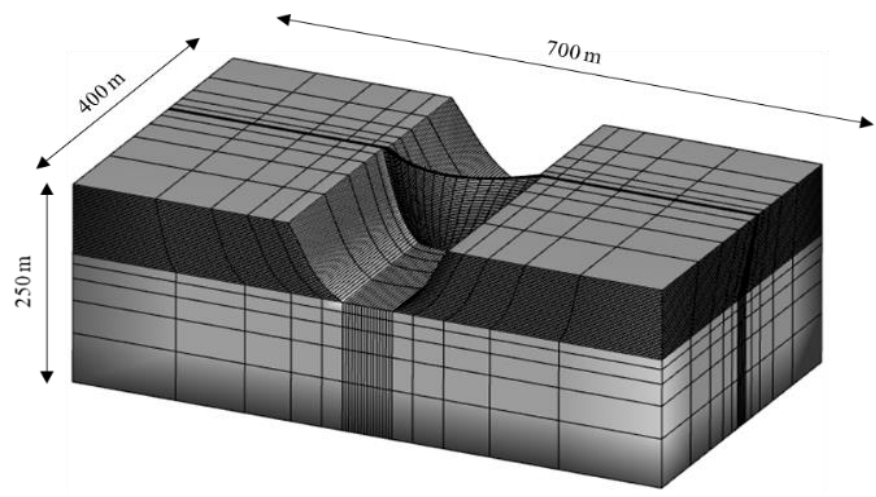

Fig. 3.Three-dimensional geometric characteristics of the Linxihe arch dam

B. Analysis of the effect of $\mathrm{MgO}$ content on thermal stress field

In this section, the dissertation will analyze the ability to improve dam body stress with different $\mathrm{MgO}$ content. The 
use of $\mathrm{MgO}$ content must meet the stability of concrete dams because the ability to compensate concrete shrinkage in different dosages will also vary. Therefore, the calculation of dam body stress using $\mathrm{MgO}$ will have to use the model of autogenous volume deformation coefficient which studied in previously section, corresponding to the $\mathrm{MgO}$ content of $0 \%$, $3 \%, 4 \%$ and $5 \%$. The temperature and thermal stress of any point in the dam body will be calculated. The construction of the dam according to the construction plan lasts from December 2020 to the end of September 2021, and the simulation time lasts until the end of September 2022. Through the simulation of the temperature field and stress field during the construction period, in order to better compare the low temperature and high temperature pouring effects, according to the pouring time, the representative points at the dam height of $26 \mathrm{~m}, 52 \mathrm{~m}$, and $80 \mathrm{~m}$. Represents these results at points upstream of the dam to show the relationship between thermal stress and various $\mathrm{MgO}$ content $(0 \%, 3 \%, 4 \%$, and $5 \% \mathrm{MgO}$ ) as shown in Fig. 4 to Fig. 7.

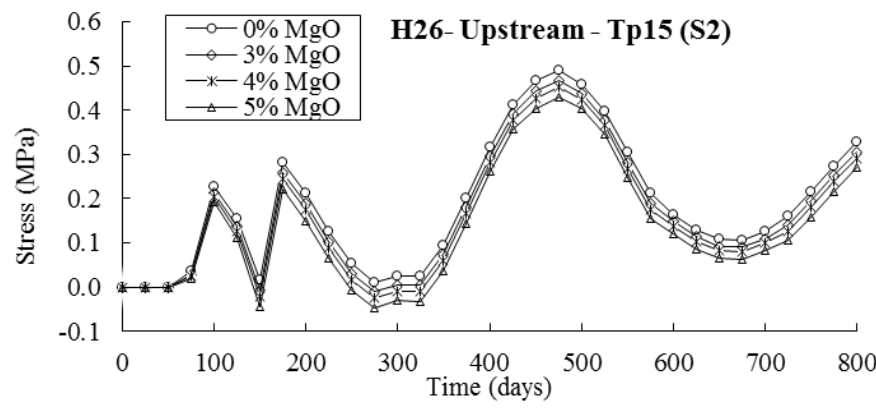

Fig. 4.Thermal stress for the point at $26 \mathrm{~m}$ of height of the dam

Maximum tensile stress for the point at $26 \mathrm{~m}$ of height of the dam are 0.47 MPa, 0.44 MPa, 0.43 MPa, 0.41 MPa, respectively, with concrete mixed with $0 \%, 3 \%$, and $4 \%$, and $5 \%$ of $\mathrm{MgO}$ conent. The occurrence time in March 2022 at the point on the upstream surface of the dam.

Maximum tensile stress for the point at $52 \mathrm{~m}$ of height of the dam are $0.85 \mathrm{MPa}, 0.79 \mathrm{MPa}, 0.76 \mathrm{MPa}, 0.70 \mathrm{MPa}$, respectively, with concrete mixed with $0 \%, 3 \%$, and $4 \%$, and $5 \%$ of $\mathrm{MgO}$ conent. The occurrence time in May 2022 at the point on the upstream surface of the dam.

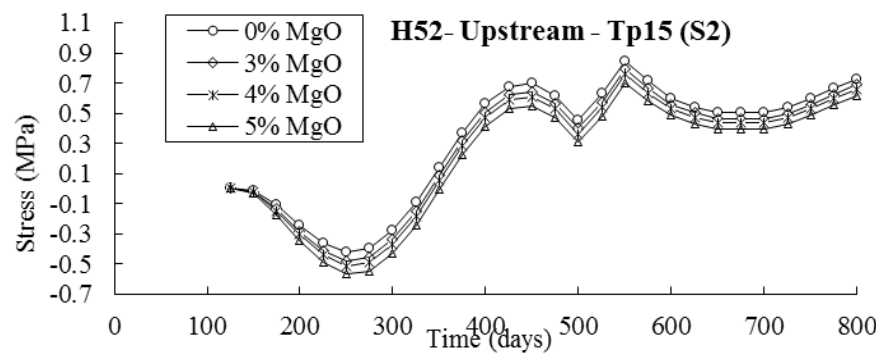

Fig. 5.Thermal stress for the point at $52 \mathrm{~m}$ of height of the dam

The comparison of stresses of the upstream, middle, and downstream points of the dam at $52 \mathrm{~m}$ of height as follows:

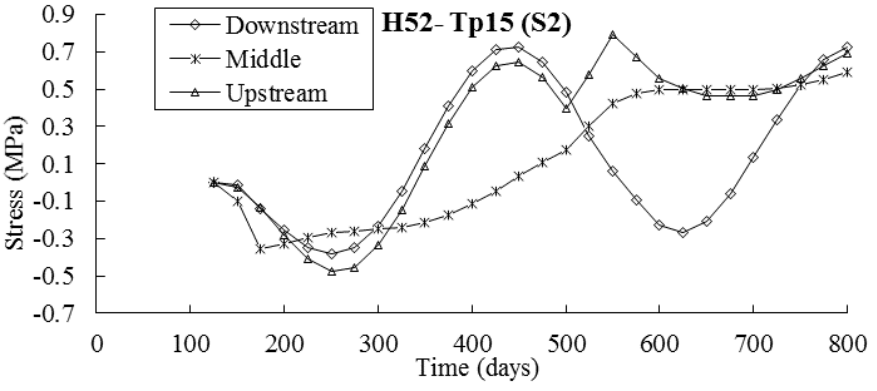

Fig. 6.Comparing stress at points at a height of $52 \mathrm{~m}$

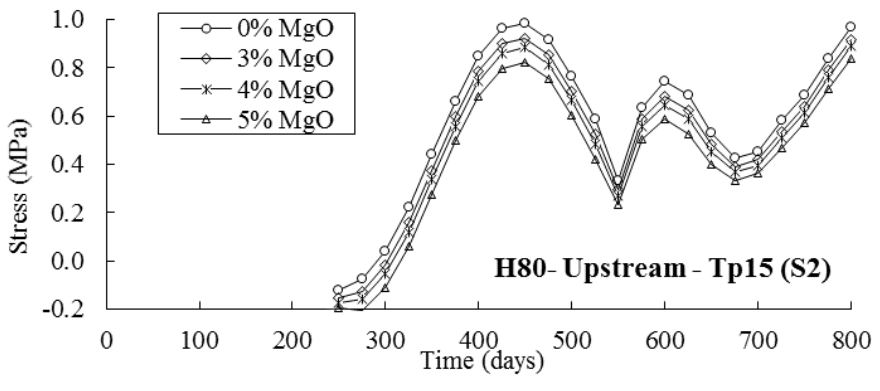

Fig. 7.Thermal stress for the point at $80 \mathrm{~m}$ of height of the dam

Maximum tensile stress for the point at $80 \mathrm{~m}$ of height of the dam are $1.00 \mathrm{MPa}, 0.94 \mathrm{MPa}, 0.90 \mathrm{MPa}, 0.85 \mathrm{MPa}$, respectively, with concrete mixed with $0 \%, 3 \%$, and $4 \%$, and $5 \%$ of $\mathrm{MgO}$ conent. The occurrence time in February 2022 at the point on the upstream surface of the dam.

The calculation results in Fig. 4 to Fig. 7 show that the maximum tensile stress of all points in the dam satisfies the permissible stress conditions. When $5 \% \mathrm{MgO}$ is added, the concrete can obtain the most effective tensile stress. The results show that Moreover to meeting the premise of stability and economic conditions, concrete with a higher $\mathrm{MgO}$ content will have a better impact on the stress state of the dam. This shows the effectiveness of using $\mathrm{MgO}$ to prevent cracking of concrete dams and control thermal stress. $\mathrm{MgO}$ can compensate the volume deformation shrinkage of concrete blocks, and is an effective way to solve the problem of temperature cracks in concrete engineering construction.

\section{CONCLUSION}

The seeking solutions to overcome traditional temperature control measures and improve the thermal stress control capabilities of concrete dams has become a hot topic in recent years. Most of these traditional methods have a certain effect on controlling temperature and preventing concrete cracking, but it cannot be denied that these measures also extend the construction time and expensive construction costs. This prompted engineers to look for new construction measures to better control the temperature and thermal stress of the concrete dam. In recent years, the method of preventing cracks in dam body by adding $\mathrm{MgO}$ to concrete has attracted more and more attention. This method makes full use of the delayed micro expansion characteristics of $\mathrm{MgO}$ to reduce or compensate for thermal shrinkage deformation of concrete, reduce the tensile stress of concrete dam, and then effectively reduce the possibility of dam cracking. So far, many concrete 
dam projects have used $\mathrm{MgO}$ as a measure to effectively control concrete cracking.

Firstly, the paper studies the theoretical basis of using $\mathrm{MgO}$ to compensate for heat shrinkage, control thermal stress, and limit concrete cracking. After that, the author introduced the experimental model and the results of calculating the AVD process of $\mathrm{MgO}$ concrete under different conditions of $\mathrm{MgO}$ content, curing temperature and time. This is followed by the introduction of a mathematical model that fully simulates the expanded properties of $\mathrm{MgO}$ concrete. This paper introduces three different $\mathrm{MgO}$ contents (including $3 \%, 4 \%$, and $5 \% \mathrm{MgO}$ ) were selected to analyze the effect of using $\mathrm{MgO}$ to control thermal stress during dam construction. Using the expansibility of $\mathrm{MgO}$ concrete to create effective compressive stress in mass concrete can control thermal stress and improve the crack resistance of concrete. The research results will produce a foundation in design calculations, produce the construction processes for concrete arch dams (speed of construction, measures to control the temperature during the construction process, construction time for a concrete layer, $\mathrm{MgO}$ content) are the factors that influence the thermal stress field of a concrete dam.

\section{ACKNOWLEDGMENTS}

This research was supported by the National Key R\&D Program of China (Grant No. 2017YFC1501100), the National Natural Science Foundation of China (Grant No. 51279090, 51679129) and sponsored by Research Fund for Excellent Dissertation of China Three Gorges University. The authors thank the reviewers for useful comments and suggestions that helped to improve the paper.

\section{REFERENCES}

[1] S. H. Zhen, Hydraulic Structures [M]. Springer, Berlin, Heidelberg, 2015

[2] V. C. Nguyen, F. G. Tong, and V. N. Nguyen, "Modeling of autogenous volume deformation process of RCC mixed with $\mathrm{MgO}$ based on concrete expansion experiment [J]," Constr. Build. Mater. vol. 210, pp. 650-659, 2019.

[3] V. C. Nguyen, X. S. Zhang, V. N. Nguyen, D. T. Phan, and G. Liu, "Experimental study on autogenous volume deformation of RCC mixed with $\mathrm{MgO}$ [C]," IOP Conf. Ser. Sci. Eng., vol. 794, pp. 1-7, 2020

[4] B. F. Zhu, "On the feasibility of building high quality arch dams without cracking and the relevant techniques [J], J. Hydraul. Eng., vol. 30, no. 10 , pp. $1155-1162,2006$.

[5] S. Q. Gong and Z. H. Liu, "Prevention measures of temperature shrinkage crack in mass concrete of highway construction [C]," in 2010 International Conference on Mechanic Automation and Control Engineering, MACE2010, 2010.

[6] S. H. Liu and K. H. Fang, "Mathematical model of autogenous volume deformation of $\mathrm{MgO}$ concrete [J]," J. Hydroelectr. Eng., no. 1, pp. 8184,2006

[7] Narwaria \& Tiwari, "Development of cracks in concrete, preventive measures and treatment methods: A review [J]," Int. Res. J. Eng. Technol., pp. 671-677, 2016.

[8] H. N. Do, "Measures to control heat during roller compacted concrete construction [K]," Yen Bai Department of Construction, 2014. [Online]. Available: http://soxaydung.yenbai.gov.vn.

[9] C. J. Du, "A Review of Magnesium Oxide in Concrete [J]," Concr. Int., vol. 27 , pp. 45-50, 2005.

[10] C. L. Chen, C. S. Tang, and Z. H. Zhao, "Application of MgO Concrete in China Dongfeng Arch Dam Foundation [J]," Adv. Mater. Res., vol. 168-170, pp. 1953-1956, 2011.

[11] P. W. Gao, X. . L. Lu, and M. S. Tang, "Shrinkage and expansive strain of concrete with fly ash and expansive agent [J]," J. Wuhan Univ. Technol. Mater. Sci. Ed., vol. 24, no. 1, pp. 150-153, 2009.
[12] L. Guo and H. Y. Cai, "Experimental Study on RCC Character of Additive $\mathrm{MgO}$ and Simulation of Crack Prevention in High Temperature Construction [J]," Adv. Mater. Res., vol. 368-373, pp. 651-654, 2011.

[13] E. Schrader and R. Mekinnon, "RCC Paving and Slabs - Deeper is Cheaper [J]," Concr. Int., vol. 11, no. 5, pp. 64-66, 1989.

[14] C. Xiehua, "Study on the Delay MgO Cement [J]," J. Nanjing Univ Chem. Technol., vol. 2, pp. 30-37, 1987.

[15] L. Guo and H. Y. Cai, "Experimental Study on RCC Character of Additive $\mathrm{MgO}$ and Simulation of Crack Prevention in High Temperature Construction [J]," Adv. Mater. Res., vol. 368-373, pp. 651-654, 2011.

[16] L. Zheng, X. H. Cui, and M. S. Tang, "MgO-type delayed expansive cement [J]," Cem. Concr. Res., vol. 21, no. 6, pp. 1049-1057, 1991

[17] L. Zheng, X. H. Cui, and M. S. Tang, "Hydration and setting time of MgO-type expansive cement [J]," Cem. Concr. Res., vol. 22, pp. 1-5, 1992.

[18] X. Y. Jing, X. H. Liu, and X. Zhang, "Thermal Stress Compensation of $\mathrm{MgO}$ Concrete in Construction of High Arch Dams in Cold Areas [J]," Adv. Mater. Res., vol. 852, pp. 427-431, 2014.

[19] J. Wang, D. K. Zhou, and Y. Q. Wang, "Technology of construction of RCC arch dam of Dahuashui hydropower station [J]," Guizhou water power, vol. 21, no. 2, pp. 40-43, 2007.

[20] Lea. F. M, "The chenistry of cement and concrete [N]," Chemical Publishing Company, 1971.

[21] Y. Zhu, Z. Xu, and L. Zhang, "Comment on dam construction technology with $\mathrm{MgO}$ concrete [G]," Hongshui River, vol. 21, no. 3. pp. $45-49,2002$.

[22] S. H. Liu and K. K. Fang, "Study on autogenous deformation of concrete incorporating $\mathrm{MgO}$ as expansive agent [J]," Environ. Ecol. Technol. Concr., vol. 302-303, pp. 155-161, 2006.

[23] P. W. Gao, S. Y. Xu, X. Chen, J. Li, and X. L. Lu, "Research on autogenous volume deformation of concrete with $\mathrm{MgO}[\mathrm{J}]$," Constr. Build. Mater., vol. 40, pp. 998-1001, 2013.

[24] X. P. Luo, "Simulation Analysis of Magnesia Concrete Arch Dam Without Contraction Joints [D]," Tsinghua University, 2002.

[25] B. F. Zhu, "On Construction of Dams by Concrete With Gentle Volume Expansion [J]," J. Hydroelectr. Eng., no. 3, pp. 1-13, 2000.

[26] Z. S. Cao, "Crack prevention technique in rapid dam construction with $\mathrm{MgO}$ weakly expending concrete [J]," Water Power, no. 6, pp. 52-53, 1994.

[27] Z. W. Liu, "Application of new technology of rapid construction of arch dam with $\mathrm{MgO}$ micro expansion concrete in Changsha Arch Dam of Guangdong Province [J]," Guangdong Water Resour. Hydropower, no. 6 , pp. $8-14,2000$.

[28] H. H. Vu, D. T. Duong, and Q. V. Vu, "New technology in building the concrete arch dam [J]," vol. 2, no. 1, pp. 1-10, 2008.

[29] W. Z. Yang, Q. X. Zhao, and G. X. Zhang, "Application and study on $\mathrm{MgO}$ concrete in dam construction," Water Resour. Plan. Des., pp. 1$13,2008$.

[30] M. X. Yuan and M. S. Tang, "Research on the autogenous volume expansion mechanism of Jilin Baishan concrete dam [J]," J. Nanjing Univ. Technol. Sci. Ed., no. 2, pp. 38-45, 1984.

[31] X. L. Lu, F. Geng, H. B. Zhang, and X. Chen, "Influence of MgO-type expansive agent hydration behaviors on expansive properties of concrete [J]," J. Wuhan Univ. Technol. Mater. Sci. Ed., vol. 26, no. 2 pp. 344-346, 2011.

[32] V. C. Nguyen, "Numerical simulation on temperature and thermal stress of MgO concrete arch dam [D]," China Three Gorges University, 2020 